\title{
Synthesis and Microstructural Characterization of Kaolin-Polyethylene Composites
}

\author{
B. Agyei-Tuffour, ${ }^{1}$ Y.D. Bensah, ${ }^{1}$ L.N.W. Damoah, ${ }^{1}$ D. Dodoo-Arhin, ${ }^{1,2}$ A. Yaya, ${ }^{1}$ E. Nyankson, ${ }^{1}$ \\ E. Annan, ${ }^{1}$ E. Sarkodee, ${ }^{1}$ J.K. Efavi ${ }^{1}$ \\ ${ }^{1}$ Department of Materials Science and Engineering, University of Ghana, Legon-Accra, Ghana \\ ${ }^{2}$ Department of Physics, Institute of Applied Materials, University of Pretoria, Pretoria 0028, RSA
}

In this article, the preparation and characterization of kaolin/polyethylene composites are presented. Microstructural characteristics of six different kaolin-polyethylene composites with varying percentage compositions of kaolin and polymer were produced using a modified melt compounding approach, was explored. The characterization methods employed are scanning electron microscopy (SEM), attenuated total reflectance mid Infrared (ATR-MIR), X-ray powder diffraction (XRD), thermogravimetric and differential thermal analysis (TGA-DTA), compressive, flexural strengths and impact resistance analysis. The implications of the results are discussed for the design of kaolin/polymer composites for constructional purposes.

\section{Introduction}

Polymer-based nanocomposites have in recent years, generated a lot of interest in the field of nanotechnology because exfoliated clays, carbon nanotubes, carbon nanofibers, exfoliated graphite, and nanocrystalline metals can generate significant mechanical properties that are advantageous to the modification of polymeric systems Yaya et al. [1] and Bensah et al. [2]. Several composites have been developed for various applications (in cars, airplanes, etc) by adding reinforcing compounds to polymers to enhance their thermal, mechanical and barrier properties according to Nam et al. [3] and Alexandre et al. [4]. However, most of these reinforced materials have poor interactions at the interface with the matrix. Macroscopic reinforcing components usually contain defects, which

Correspondence to: B. Agyei-Tuffour; e-mail: bagyei-tuffour@ug.edu.gh Contract grant sponsor: University of Ghana Research and Conferences Committee (UG-RCC); Office of Research, Innovation and Development (ORID). become less important as the particles of the reinforcing are reduced in size as reported by Luduena et al. [5].

The significant advantages of using polymeric nanocomposites over conventional materials are that of processing ease, manufacturing versatility and low over-head production cost. Polymers are widely used due to their ease of production, light weight and ductile nature. In comparison with metals and ceramics, polymers are much more inferior in mechanical properties Anjana et al. [6]. The layered silicates (clay minerals) commonly used for the preparation of polymer composites belong to the family of 2:1 phyllosilicates, with kaolinite being one of the most common of such clay minerals Fowden et al., [7]. Their layered tetrahedral silica sheets are linked through oxygen atoms to the octahedral alumina sheets Fowden et al., [7]. These layers are separated by galleries where cations such as $\mathrm{Na}^{+}, \mathrm{K}^{+}$, etc., are present to counterbalance the negative charge of the aluminosilicate sheets arising from isomorphic substitution of $\mathrm{Al}$ or $\mathrm{Si}$ with other metals. The replacement of the cations by an appropriate surfactant (organic phase) renders the kaolinite hydrophobic, thus allowing it to interface with different polymer matrices according to Bertini et al., [8].

Polyethylene on the other hand has become one of the most widely used polyolefin polymers for grocery, piping and packaging bags, car fuel tanks, toys etc. Polyolefin polymers have no polar group in its structure; also the homogeneous dispersion of the kaolin in polyethylene is hardly realized. In this respect kaolin is normally modified organically to enhance its interaction with the polyethylene matrix but even organically modified clay does not disperse well in polyethylene due to its relatively hydrophobic nature according to Wang et al, [9]. Research has established that for polymer-layered silicate (clay) composites, the enhancement of the mechanical, thermal, barrier and microstructural properties for specific applications strongly depends on the attainment of an effective dispersion of the filler material in the polymer matrix (Mittal [10] and Heinemann et al. [11]). 
The main challenge however facing the preparation of polymer nanocomposite using nanoclay such as kaolin as reinforcement is that, clay is naturally hydrophilic whereas polyethylene has no polar group in their backbone and hence one of the most hydrophobic polymers. To overcome this difficulty and to ensure proper dispersion, organic modifiers such as oils or surfactants which contains organic cations like alkyl ammonium, alkyl amine, etc., are used to replace the inorganic cations $\left(\mathrm{Na}^{+}\right)$of the clay (Lei et al., [12]). According to literature, the use of modified and unmodified kaolin has been studied extensively. For instance, a modified $\mathrm{C}_{60}$ powder in Hydrochloric acid and benzalkonium chloride modifier can adequately modify Montmorillonite to perform a cation exchange between the clay and the modifier. Also, 4,5-imidazole dicarboxylic acid dissolved in $200 \mathrm{ml}$ of deionized water is able to modify clays to perform an anion exchange between [ $\left.\mathrm{LiAl}_{2}\right] \mathrm{LDH}$ and 4,5-imidazole dicarboxylic acid [13]. Nanocomposites containing polyethylene (PE) and montmorillonite clay organically modified (OMMT) with quaternary ammonium salts obtained via direct melt intercalation has also been reported by Araujo et al. [14]. In addition, a modified clay intercalated with a modifier having a conjugated double bond and capable of producing free radicals when heated according to [13] etc. However, limited information is available on the modification of the polyethylene to improve interfacial adhesion and improved dispersion of kaolin in a polyethylene matrix. The modification of the polyethylene may help in two basic ways. Firstly, it will reduce the viscosity of the polymer melt to enhance uniform dispersion of the filler and make processing of the composite in terms of molding of different shape forms, and secondly, to utilize the alkyl, hydroxyl, carboxylic and the ester components of the triglyceride molecules in the oil to bond the polyethylene and the kaolin particles. In addition, the triglyceride molecules through their hydrophilic functional groups favour the formation of a possible exfoliated structure and also offer the ability to control the number of polar groups through chemical modifications [11].

In this article therefore, we processed polyethylenekaolin composites using vegetable oil and investigated the microstructural and mechanical properties of the unmodified kaolin and modified polyethylene composites. The melt compounding technique was adopted and the composites have been characterized using X-ray fluorescence (XRF), X-ray diffraction (XRD) and scanning electron microscopy (SEM). The others included Fourier transform infrared spectroscopy ATR-MIR (FTIR), differential thermal and thermogravimetry (TGA/DTA) and mechanical testing techniques.

\section{Materials and method}

Low density polyethylene waste bags (polymer) with density $0.915-0.935 \mathrm{~g} \mathrm{~cm}^{-3}$, melt flow index (MFI) of 0.18 , the degree of crystallinity between 40 and 50 were collected from households and litter bins of waste manage- ment corporations and thoroughly washed with copious amount of water, dried and shredded into smaller pieces. The kaolin used was mined from deposits at Kibi in the Eastern region of Ghana and then washed to remove all impurities, before being dried in an oven at a temperature of $105^{\circ} \mathrm{C}$ for $3 \mathrm{~h}$. The kibi kaolin was then ball milled and sieved into particle sizes ranging from 50 to $125 \mu \mathrm{m}$. The mixing solvent used was lipid from commercially refined vegetable oil.

Batches of six different compositions were formed using the melt-compounding technique (Bensah et al., [2]), where the polyethylene was melted in a vegetable oil at $245^{\circ} \mathrm{C}$. The measured amount of kaolin was introduced into the oil-polyethylene melt under constant stirring (to avoid lumping) till a uniform mixture was obtained. Casting was done at $245^{\circ} \mathrm{C}$ in a $1 \mathrm{~cm} \times 1 \mathrm{~cm} \times 2 \mathrm{~cm}$ and $2 \mathrm{~cm} \times 3$ $\mathrm{cm} \times 5 \mathrm{~cm}$ aluminum molds and was cooled to room temperature for further characterization.

$\mathrm{X}$-ray fluorescence mineralogical composition of the as-prepared kaolin was determined using a Spectro-X Lab 2000 X-ray fluorescence spectrometer (AMETEK USA).

X-ray powder diffraction (XRD) patterns were collected on an XPERT-PRO diffractometer (PANalytical $\mathrm{BV}$, Netherlands) with theta/theta goniometer, operating a cobalt tube at $35 \mathrm{kV}$ and $50 \mathrm{~mA}$. The goniometer is equipped with automatic divergence Slit and a PW3064 spinner stage. The instrumental contribution to the line broadening was characterized using the NIST SRM 660a $\left(\mathrm{LaB}_{6}\right)$ standard Cline et al., [15] and all peak profiles simultaneously fitted with symmetrical pseudo-Voigt functions whose width and shape were constrained according to the Caglioti et al., [16] formulae. The XRD patterns of all specimens were recorded in the $5.0^{\circ}-60^{\circ}$ $2 \theta$ range with a step size of $0.017^{\circ}$ and a counting time of 14 s per step. Qualitative phase analysis was conducted using the X'pert Highscore plus search match software.

Scanning electron microscopy analysis was conducted using an ultra-high vacuum and high resolution Zeiss Ultra plus 55 Field Emission scanning electron microscopy (FESEM). Samples were metalized with carbon coating prior to the analysis. Images were acquired at magnifications of $1,000 \times\left(\mathrm{a}_{1}, \mathrm{~b}_{1}, \mathrm{c}_{1}, \mathrm{~d}_{1}, \mathrm{e}_{1}, \mathrm{f}_{1}\right)$ and $30,000 \times\left(a_{2}, b_{2}, c_{2}, d_{2}, e_{2} f_{2}\right)$.

Attenuated total reflectance (ATR) mid infra-red spectra were recorded on a HYPERION 3000 (Bruker Optics) instrument in the $4000-400 \mathrm{~cm}^{-1}$ range with $2 \mathrm{~cm}^{-1}$ resolution; the OPUS program was employed for the ATR-MIR analysis. Transmission FTIR spectra were recorded on a HYPERION 3000 Vertex 70v (Bruker optics) spectrometer in the $4000-400 \mathrm{~cm}^{-1}$ range with 2 $\mathrm{cm}^{-1}$ resolution. The powder samples were measured without the addition of $\mathrm{KBr}$. Sample compartment was evacuated during acquisition and the contact between the sample and the attenuated total reflectance (ATR) diamond crystal is $2 \mathrm{~mm}$ diameter. Spectra were recorded and analyzed with the Opus software. 
To investigate the thermal stability of the various phases, the composite samples were studied by DTA/ TGA under air flow of $50 \mathrm{~mL} \mathrm{~min}{ }^{-1}$. The samples were thermally analyzed by placing $15.89 \mathrm{mg}$ of the specimens in an alumina $\left(\mathrm{Al}_{2} \mathrm{O}_{3}\right)$ crucible (100 $\mathrm{mg}$ capacity), subjected to a linear heating ramp between 15 and $850^{\circ} \mathrm{C}$ at a rate of $10^{\circ} \mathrm{C} \mathrm{min}{ }^{-1}$ and a cooling rate of $50^{\circ} \mathrm{C} \mathrm{min}^{-1}$, using a standard SDT Q600 (V20.9 Build 20) TG/DTA instrument. The test measurements were made for the mass change (loss) of the sample as a function of the temperature and the phase changes by the adsorption or the emission of energy. A sapphire standard was used to calibrate the thermal response due to heat flow as well as the temperature prior to analysis.

The hardness of each of the as-produced samples was carried out using the Vickers indentation hardness technique on a diamond indenter equipped Fun-700 (Future Tech Corporation) micro-hardness system. A load of 98 $\mathrm{mN}$ was applied for $30 \mathrm{~s}$ on all samples measured and the average values of a total of four indentations per sample were recorded.

Compressive tests were carried out on a C-46L2 (CONTROLS, Italy) Universal Materials Testing Apparatus equipped with a maximum $3 \mathrm{kN}$ cell at room temperature following the ASTM D6641/D6641M - 09 standard. The as-produced samples $(1.5 \mathrm{~cm} \times 2.5 \mathrm{~cm})$ were compressed at a constant compression rate of $1 \mathrm{~mm} \min ^{-1}$ until the bodies were fragmented. The material's response (maximum stress or fracture) to the applied load was measured for four (4) samples of each preparation batch and the average values recorded.

$$
C . S=\frac{\operatorname{Force}(S)}{\operatorname{Area}\left(A_{c}\right)}
$$

where $S$ is the Average Compressive Force exerted on both samples and $A_{\mathrm{c}}$ is the Area of composite sample.

The impact resistance test was carried out using drop weight equipment with a hammer weighing about $14 \mathrm{~kg}$. The hammer was twice released from a height of $380 \mathrm{~mm}$ to fall freely between two vertical guides, to crush the composite in the cup. The weights prior to the test were recorded. The crushed sample was sieved in $2.36 \mathrm{~mm}$ standard sieve and weighed. The difference between the sieved weight and the initial weight was determined and calculated as a percentage of the original weight. Two tests were carried on the same sample type and the average values determined as the impact values using:

$$
I R=\left(1-\frac{W_{L}}{W_{i}}\right) \times 100 \%
$$

where $I R$ is the impact resistance in per cent, $W_{\mathrm{L}}, W_{\mathrm{i}}$ are the per cent loss of material after test and weight of composite before test respectively. The three-point bending tests of the samples were carried out following standard ISO/ASTM procedures and recommendations (ISO 14125,

\begin{tabular}{|c|c|}
\hline Oxides & Composition (wt $\%$ ) \\
\hline $\mathrm{SiO}_{2}$ & 45.81 \\
\hline $\mathrm{Al}_{2} \mathrm{O}_{3}$ & 39.64 \\
\hline $\mathrm{TiO}_{2}$ & 1.46 \\
\hline $\mathrm{K}_{2} \mathrm{O}$ & 0.84 \\
\hline $\mathrm{CaO}$ & 0.01 \\
\hline $\mathrm{Na}_{2} \mathrm{O}$ & 0.02 \\
\hline Others & 0.20 \\
\hline LOI & 11.07 \\
\hline
\end{tabular}

Table 1. The chemical composition of the kaolin clay.

ASTM C99/C99M-09). The flexural tests were performed on an Instron 5900 universal testing machine equipped with a Test Star II (MTS) controller and a $5 \mathrm{kN}$ load cell under $\approx 1 \mathrm{~mm} \mathrm{~min}^{-1}$ displacement cross-head feed rate.

Four test bar specimens from each batch with dimensions of $10 \mathrm{~mm} \times 10 \mathrm{~mm} \times 200 \mathrm{~mm}$ were prepared for the flexural tests and the average values were determined according to $E q$. 3, where $\boldsymbol{F}$ is load in Newton's, $\boldsymbol{d}$ is breadth, $\boldsymbol{h}$ is depth, $\boldsymbol{L}$ is distance between supports used.

$$
\sigma=\frac{3 F L}{2 d h^{2}}
$$

\section{Results and Discussion}

\section{XRF and XRD Analysis}

Table 1 presents the X-ray fluorescence (XRF) data of the kaolin. The data indicates Silica to Alumina ratio of 1.16, which is very close to the ISO standard of 1.18. This also indicates the extent to which kaolin is able to bond successfully with low density polyethylene and enhances its suitability as a reinforcement material. A strong interaction between the dispersed clay particles and the polymer matrix are indications of good thermal and mechanical properties in the composite sample according to Liqiang [17].

The quality (order-disorder) of the kaolin sample was characterized from the XRD pattern shown in Fig. 1 using the Hinckley index (HI) Hinckley [18]. The Hinckley's index (HI) which is used in the determination of degree of crystallinity is the ratio of (i) the sum of the heights of the $(1 \overline{1} 0)$ and $(11 \overline{1})\left(23.28^{\circ}\right.$ and $26.79^{\circ}$, respectively) diffraction peaks measured from the inter-peak background, and (ii) the height of the (110) peak measured from the general background. It is generally known that as the crystallinity decreases, the proportion of random shifts in kaolinites between adjacent layers by $\pm n b / 3$ increases, resulting in a decrease in resolution of neighboring peaks and an hence an increase in the inter-peak diffraction intensity. Simultaneously, an increase in the frequency of defects would decrease the absolute intensity of the (110) peak. The arithmetical blend of these two estimates (intensity of peaks and the inter-peak background) yields 


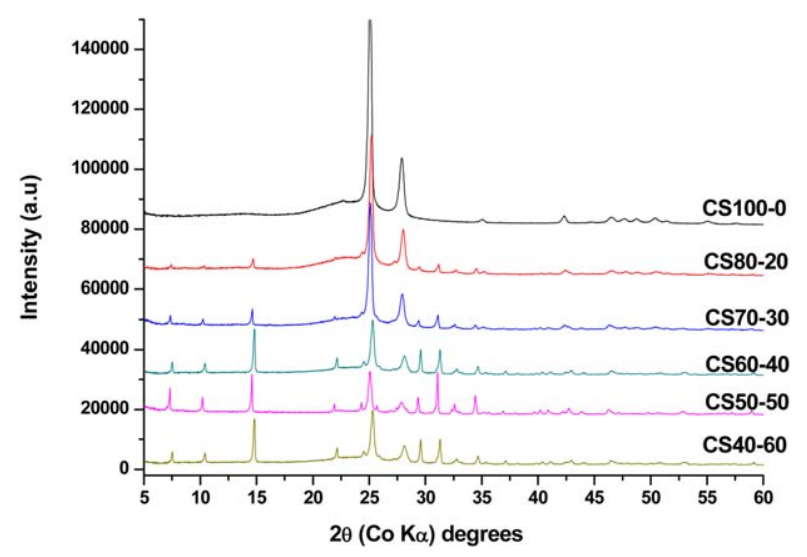

Fig. 1. shows the combined XRD patterns and their unique peak positions for the pristine kibi kaolin; CS100-0, variation of polyethylene and kaolin reinforced composites; CS80-20 to CS40-60, etc. [Color figure can be viewed in the online issue, which is available at wileyonlinelibrary.com.]

the dimensionless number (index) which normally varies between $\approx 0.2$ and $\approx 1.5$; the larger the value of the index, the greater the "crystallinity." The Kibi kaolin is found to possess a well crystallized lattice structure with minimal lattice defects. This is supported by the sharp, narrow and intense XRD peaks as shown in Fig. 1a-f with a Hinckley's index of (0.9). Furthermore, the average crystallite size of $447.25 \AA$ for the kaolin sample was calculated by the Scherrer broadening method using the basal 002 reflection with peak position at $\left(31.28^{\circ}, 2 \theta\right)$ according to Scherrer [19].

Figure 2, shows the SEM micrographs of the various composites and that of the pristine polyethylene polymer (Fig. $2 \mathrm{a}_{1}$ and $\mathrm{a}_{2}$ ) with different magnifications $(1000 \times)$ and $(30,000 \times)$. It is observed that, the pristine polymer had a uniform composition with reference to the polymer/kaolin compositions. The micrographs show clearly at lower kaolin percentage, that there is a homogeneous dispersion of the kaolin in small tactoids within the polymer matrix without any sign of agglomeration (Fig. $2 b_{1}$ and $d_{2}$ ). However, as the kaolin content is higher, the kaolin is seen to agglomerate in the polymer (Fig. $2 \mathrm{e}_{1}, \mathrm{e}_{2}-\mathrm{f}_{1}$, and $\mathrm{f}_{2}$ ).

CS60-40 (Fig. $2 \mathrm{~d}_{1}$ and $\mathrm{d}_{2}$ ) showed a high degree of dispersion of kaolin in the polymer matrix and a low tendency toward agglomerate formation as compared to samples with greater kaolin contents beyond $40 \mathrm{wt} \%$ as seen in CS50-50 (Fig. 2 $\mathrm{e}_{1}$ and $\mathrm{e}_{2}$ ) and CS40-60 (Fig. 2 $\mathrm{f}_{1}$ and $\mathrm{f}_{2}$ ). This is due to the poor affinity of the polar kaolin to the polyethylene. Hence, as the amount of clay becomes higher, the clay particles gain much higher tendency to agglomerate and forming clusters compared to when the clay content is lower, a trend observed virtually in all the SEM images (Fig. $2 b_{1}-f_{2}$ ) starting from a lower to higher kaolin content in the polyethylene matrix.

The ATR-MIR spectra for the various kaolin/polymer composites as shown in Fig. 3 exhibit characteristic vibrational modes. The bands at $3,620 \mathrm{~cm}^{-1}$ corresponds to the inner $\mathrm{OH}$ stretching, $3,695 \mathrm{~cm}^{-1}$ corresponds to the in-phase stretching of the three inner-surface $\mathrm{OH}$ groups; bands at 3,669 and $3,652 \mathrm{~cm}^{-1}$ corresponds to the antiphase stretching modes of the inner-surface $\mathrm{OH}$ groups. The bands around 1,008 and 1,032 $\mathrm{cm}^{-1}$ can also be attributed to the anti-symmetric stretching of the equatorial $\mathrm{Si}-\mathrm{O}$ bonds whiles those around $1,112 \mathrm{~cm}^{-1}$ correspond to the symmetric stretching of the equatorial $\mathrm{Si}-\mathrm{O}$ bonds, all attributed to kaolinite.

The functional groups responsible for absorption at each frequencies of coconut oil spectrum are as follows: the asymmetrical stretching vibration of methyl $\left(-\mathrm{CH}_{3}\right)$ causes a shoulder at wavenumber of $2,954 \mathrm{~cm}^{-1}$, whereas the symmetrical vibration of methyl band is not observed. Either asymmetrical or symmetrical stretching vibration of methylene band has been observed at $\sim 2,924 \mathrm{~cm}^{-1}$ and near $2,852 \mathrm{~cm}^{-1}$, respectively by Guillen and Cabo, [20]. The absorption of carbonyl $(\mathrm{C}=\mathrm{O})$ groups from ester linkage of triglycerol of coconut oil is usually observed around $1732 \mathrm{~cm}^{-1}$ with a strong intensity due to the great difference in electronegativity between the carbon and hydrogen atoms as reported by Pavia et al., [21]. The band with medium intensity around $1465 \mathrm{~cm}^{-1}$ is attributed to the methylene $\left(-\mathrm{CH}_{2}\right)$ bending vibration around $1,417 \mathrm{~cm}^{-1}$ is attributed to the rocking vibrations of $\mathrm{C}-\mathrm{H}$ bonds in alkenes. The vibration of $\mathrm{CH}_{3}-$ groups on symmetrical bending mode can be seen around wavenumber $1,377 \mathrm{~cm}^{-1}$. The bands around 1,228, 1,155, and $1,109 \mathrm{~cm}^{-1}$ are attributed from the vibrations of stretching mode from the $\mathrm{C}-\mathrm{O}$ group in esters, Silverstein and Webster [22]. An absorption band around frequency of $962 \mathrm{~cm}^{-1}$ is related to bending vibration of cis- disubstituted olefinic groups. Finally, absorption peak around frequency $721 \mathrm{~cm}^{-1}$ is resulted from the rocking vibrations of methylene group which overlaps with bending vibration on out of plane mode of alkenes with cis-disubstituted Guillen and Cabo, [20]. The most intense band for kaolinite is the $636.5 \mathrm{~cm}^{-1}$ mode. This band has been attributed to a $\mathrm{Si}-\mathrm{O}-\mathrm{Si}$ stretch Lazarev [23]. The bands around 426,469 and $509 \mathrm{~cm}^{-1}$ have been attributed to the $\mathrm{Si}-\mathrm{O}$ bending vibration according to Farmer [24]. Also, the $3,620 \mathrm{~cm}^{-1}$ IR band for kaolinite has been assigned to the inner sheet hydroxyl as reported by Ledoux; Wada; White and Rouxhet [25-28]. The characteristic peaks of polyethylene are around 2,918, 2,850, 1,473, 730, and $719 \mathrm{~cm}^{-1}$. On our as-produced composites, these stretching modes are ascribed to $2,920 \mathrm{~cm}^{-1}\left(\mathrm{CH}_{2}\right.$ asymmetric stretching); 2,851 cm $\mathrm{cm}^{-1}\left(\mathrm{CH}_{2}\right.$ asymmetric stretching); $1,473 \mathrm{~cm}^{-1}\left(\mathrm{CH}_{2}\right.$ bending); $1,465 \mathrm{~cm}^{-1}\left(\mathrm{CH}_{2}\right.$ bending), $1,176 \mathrm{~cm}^{-1}$ (wagging of $\left.\mathrm{CH}_{2}\right), 1,050 \mathrm{~cm}^{-1}\left(\mathrm{CH}_{2}\right.$ twisting), $730 \mathrm{~cm}^{-1}\left(\mathrm{CH}_{2}\right.$ twisting), $720 \mathrm{~cm}^{-1}\left(\mathrm{CH}_{2}\right.$ rocking).

\section{Thermal Characteristics of Composites}

The results of differential thermal analysis (DTA) and thermogravimetric analysis (TGA) of the composites in Fig. 4 show a glass transition temperature ranges of between 280 and $400^{\circ} \mathrm{C}$. It is observed that sample CS60- 


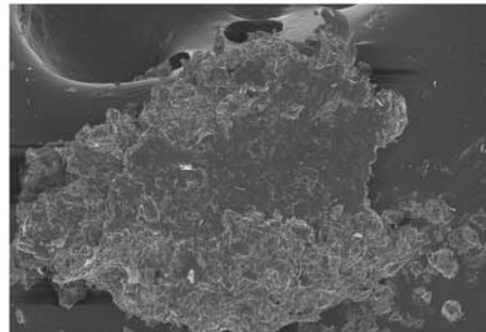

(a $)$

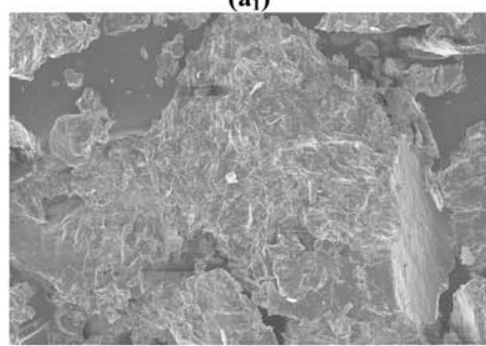

(b)

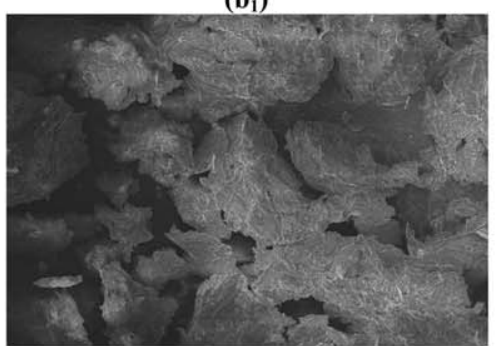

(c $\left.c_{1}\right)$

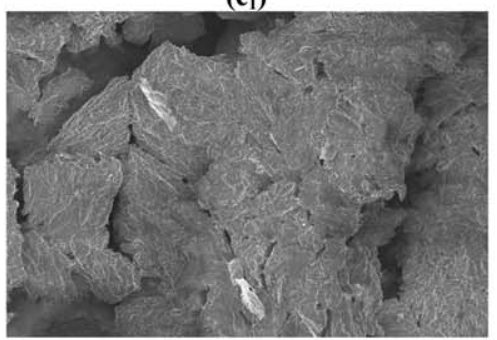

(d)

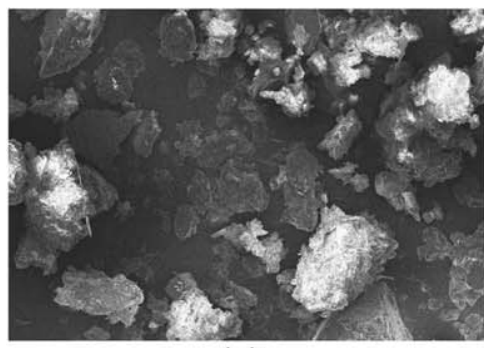

(e

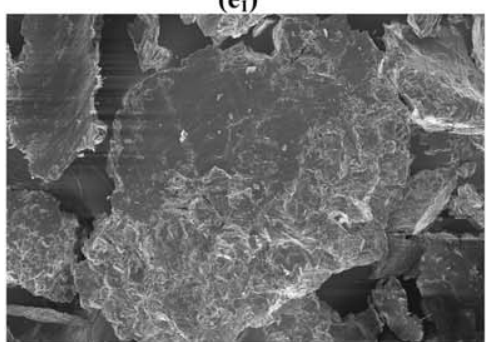

(f)

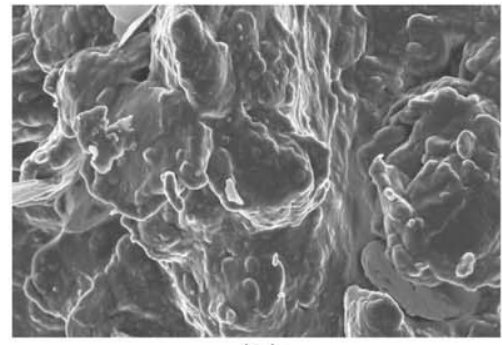

(a)

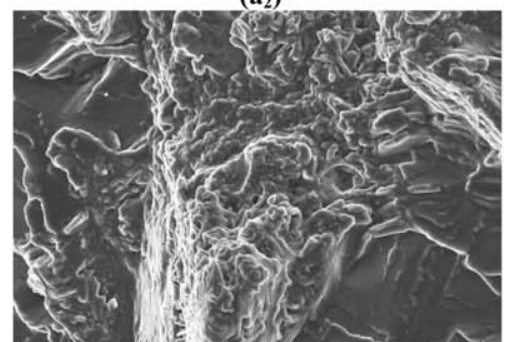

(b)

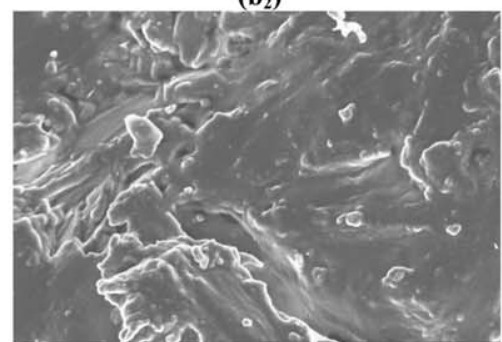

(c $\left.c_{2}\right)$

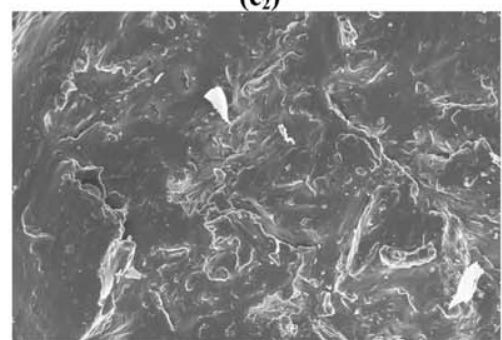

(d)

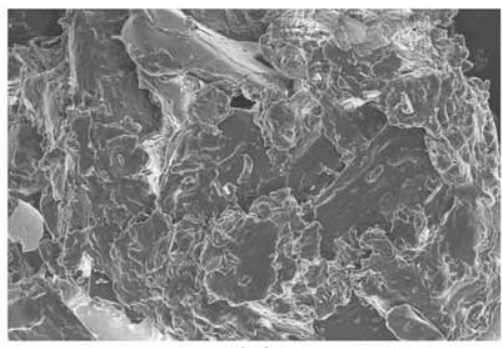

(e)

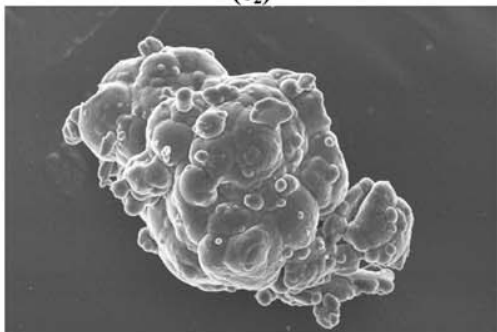

(f)

Fig. 2. SEM images showing the surface morphologies of the composite batch compositions: $\left(a_{1}-a_{2}\right)$ CS100-0, $\left(\mathrm{b}_{1}-\mathrm{b}_{2}\right)$ CS80-20 ( $\left(\mathrm{c}_{1}-\mathrm{c}_{2}\right)$ CS70-30, $\left(\mathrm{d}_{1}-\mathrm{d}_{2}\right)$ CS60-40, $\left(\mathrm{e}_{1}-\mathrm{e}_{2}\right)$ CS50-50 and $\left(\mathrm{f}_{1}-\mathrm{f}_{2}\right)$ CS40-60 at $1 \mathrm{KX}$ and $30 \mathrm{KX}$, respectively. 


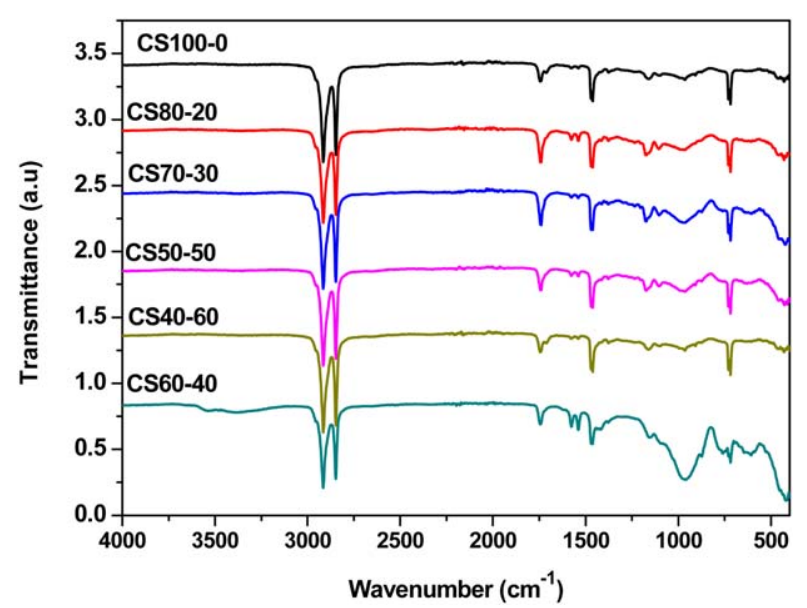

Fig. 3. ATR-MIR patterns for: the pristine polymer CS100-0 and the variation of the components of the pristine polyethylene and the kaolin reinforced composites. [Color figure can be viewed in the online issue, which is available at wileyonlinelibrary.com.]

40 showed the highest glass transition temperature $\left(T_{\mathrm{g}}\right)$ of $390^{\circ} \mathrm{C}$ whereas the other samples showed their $T_{\mathrm{g}}$ 's between 280 and $300^{\circ} \mathrm{C}$. This is attributed to a more uniform mix between the kaolin and the polyethylene evolving into a strengthened composite making it able to withstand a higher thermal stress.

All the samples showed no significant difference in the crystallization temperature $\left(T_{\mathrm{c}}\right)$ and melting temperature $\left(T_{\mathrm{m}}\right)$. Samples CS50-50 and CS40-60 improved retardation to combustion compared to sample CS100-0 which is mainly due to the high kaolin content which act as combustion suppressant as reported by Bensah et al., [2]. The pristine batch compositions CS100-0 was completely burnt out at $500^{\circ} \mathrm{C}$ due to the organic nature of compositions leaving behind a residue of $0.89 \%$ of the starting material. However, batch samples CS80-20, CS70-30, CS60-40, CS50-50, and CS40-60 had residues of 6.5, $10.0,20.97,44.22$, and $70.45 \%$, respectively at $500^{\circ} \mathrm{C}$ close to their $T_{\mathrm{m}}$ points and the corresponding exothermic peaks indicating that the losses are mainly due to the removal of organic compounds and gaseous materials by combustion rather than a decomposition reaction.

\section{Mechanical Properties of Composites}

Figure 5a shows the effect of filler content on the impact resistance and hardness of the polymer ceramic composite. The calculated impact resistance ranged from $97 \%$ for CS $60-40$ to $78 \%$ for CS $80-20$. Generally, the composites showed gradual decrease in impact resistance from the pure polymer until $40 \mathrm{wt} \%$ kaolin (the highest recorded filler content with increased strength). Beyond $40 \mathrm{wt} \%$ kaolin content, there was a sharp decrease in the impact resistant values to below $84 \%$. A similar trend was observed in the hardness profile except that, there was a continuous increase in hard beyond $40 \mathrm{wt} \%$. This was because, there was an improved dispersion in the melted polyethylene and a homogenous mix was achieved in CS 60-40. However at higher kaolin loadings, there was a depletion of binder in the composite which led to limited polymer-kaolin intercalations. The improved mechanical properties were largely dependent on a higher degree of bonding at the matrix-particle interfaces and also due to the kaolin powder's ability to distribute the applied stress over a large volume. This helped to prevent propagation of cracks by carrying large part of the load, Mustapha [30]. Generally, high kaolin content causes the composites to improve in strength but with a reduction in ductility.

Figure $5 \mathrm{~b}$ and $\mathrm{c}$ present the effect of filler content on the compressive and flexural strength of the composites. It can be seen that, the compressive and flexural strengths of the composites experienced gradual increase in strength when the kaolin content was increasing until beyond $40 \mathrm{wt} \%$. The CS60-40 sample recorded the highest compressive and flexural strengths in both profiles as observed in the impact resistance graphs. This observation can also be attributed to the uniform dispersion of the filler in the matrix and improved bonding by the polyethylene. However, further increase in kaolin content above 40 wt $\%$ recorded a decreasing trend with low strength values of about 3.6 MPa. This was because, the amount of polymer compared to kaolin had reduced which led to a reduction in the binding effect between the two and resulted in the formation of agglomerates of kaolin, and polyethylene. The segregation of the polymer from the kaolin, and the formation of clusters in the composite led to the formation of pores as reported by Jordan et al., [31] and Domka et al., [32]. The overall strength of the composite reduced sharply because, stresses tend to concentrate at points around the agglomerates. This was in agreement with the report by Boriek et al., [29] on the stress distribution of particle reinforced composites where they showed that high packing factor leads to a low magnitude of setting stresses. Thus, samples with higher compressive strengths will have higher packing factors which lower the magnitude of the setting stresses in the composite. Higher packing factor also indicate an increase in porosity in the polymer matrix and enhance homogenous dispersion of the filler. The flexural strengths were generally observed to be low due to the fact that the sample became more brittle at high loading. Inherent defects in the kaolin and the uneven stress distribution led to the agglomerates bearing most of the applied load.

\section{Conclusion}

XRD and SEM micrographs of the composite formulations indicate that high packing factor leads to a low magnitude of setting stresses and a more homogeneous mixing and higher compressive strength values in agreement with literature data. The XRD peaks showed that the Kibi kaolin possesses a well crystallized lattice 


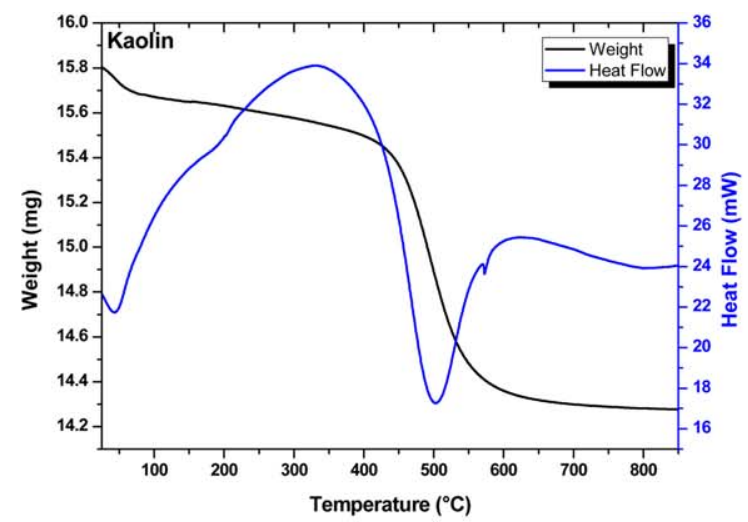

(a)

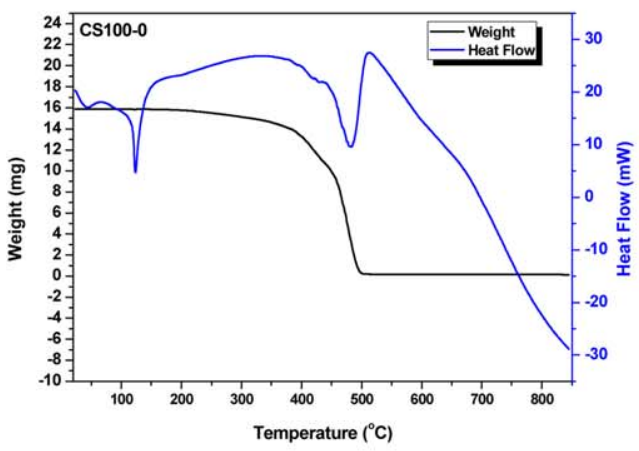

(b)

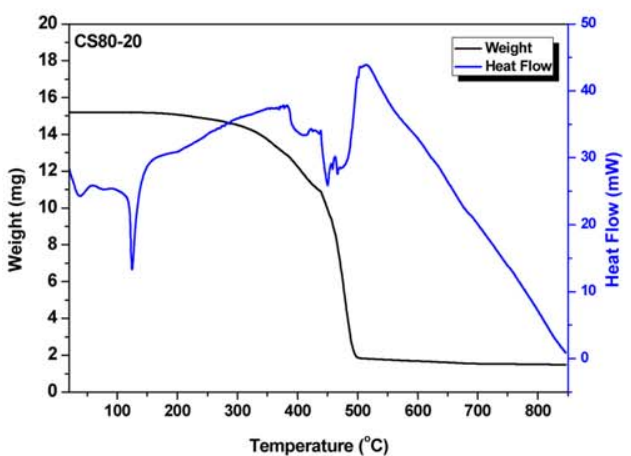

(d)

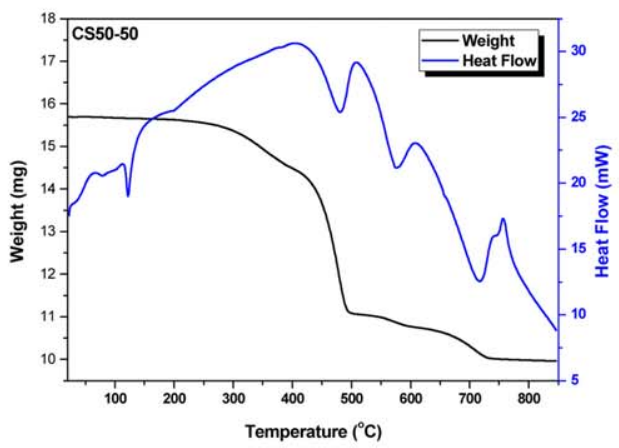

(f)

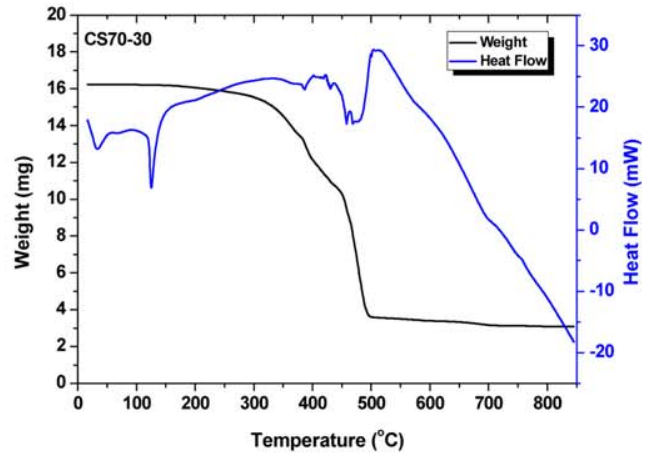

(c)

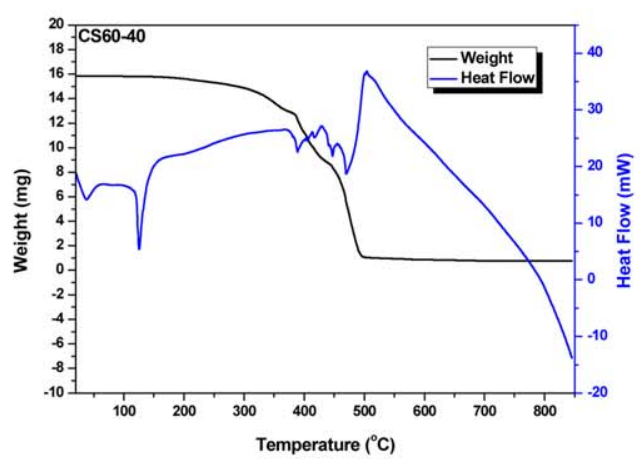

(e)

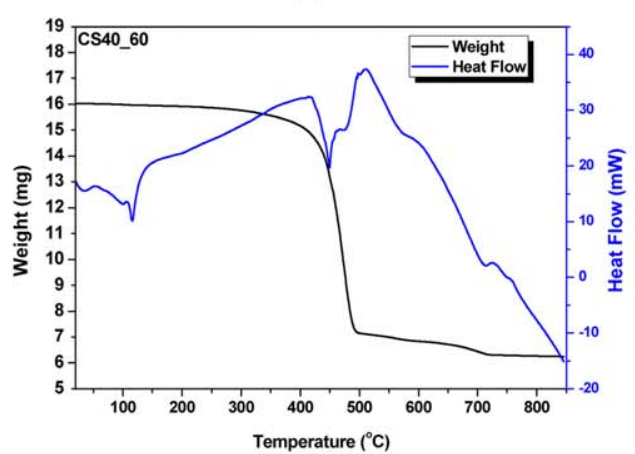

(g)

Fig. 4. Presents DSC-TGA thermographs of: (a) Pristine kaolin, (b) CS100-0, (c) CS80-20, (d) CS70-30, (e) CS60-40, (f) CS50-50, and (g) CS40-60. [Color figure can be viewed in the online issue, which is avail-able at wileyonlinelibrary.com.] 


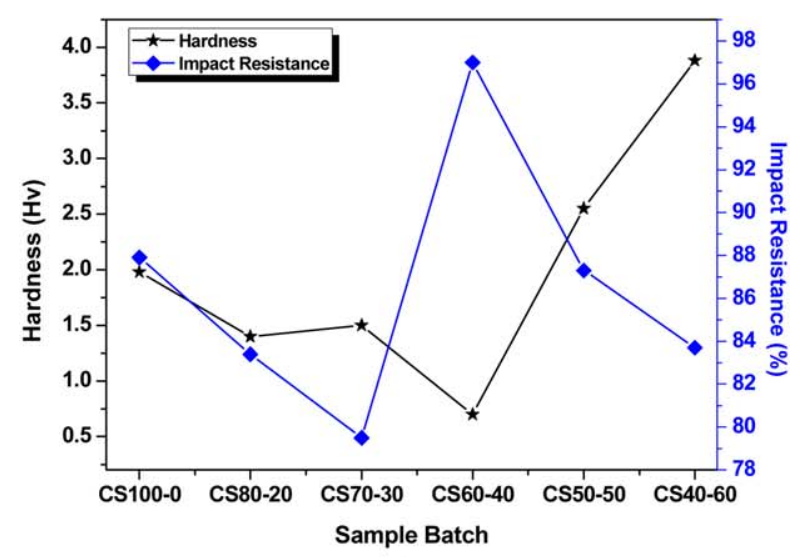

(a)

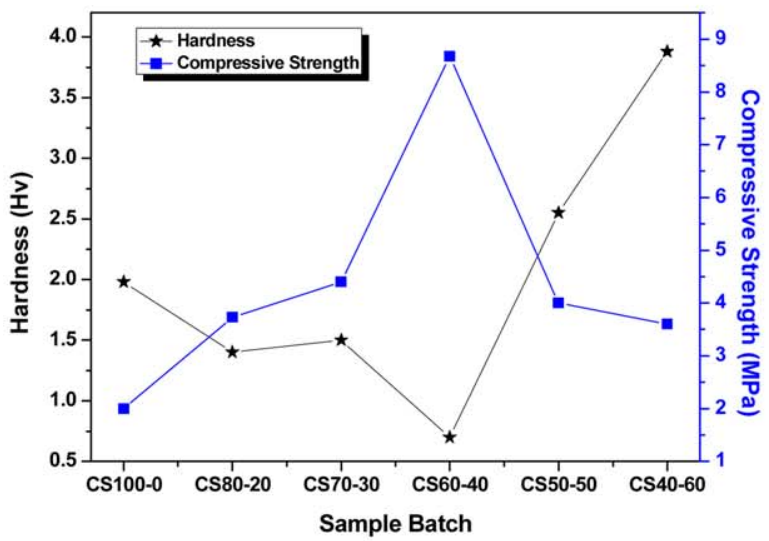

(b)

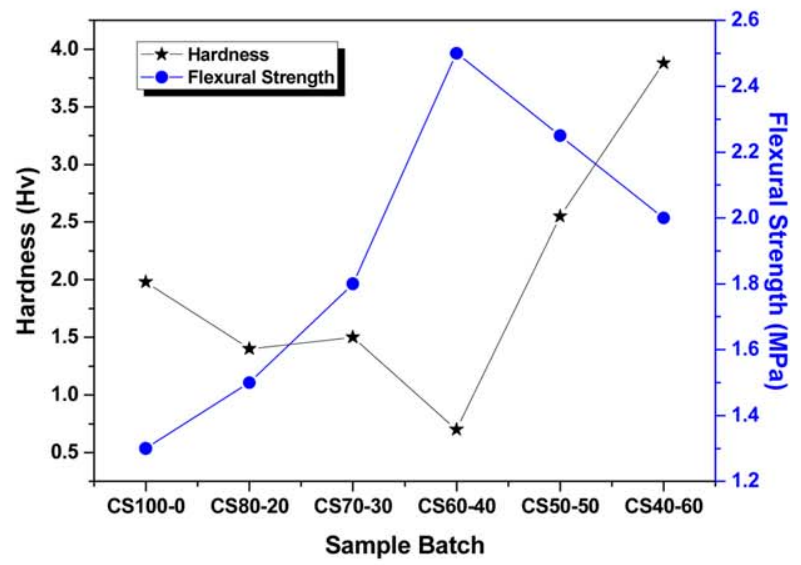

(c)

Fig. 5. Presents the effects of batch composition on the mechanical properties of the composites; (a) Impact resistance and Hardness (b) Compressive strength, and (c) flexural strength of the composites. [Color figure can be viewed in the online issue, which is available at wileyonlinelibrary.com.]

structure with minimal lattice defects and the average crystallite size of $44.7 \mathrm{~nm}$.

The TG-DTA curve revealed that CS60-40 has the highest feasible processing temperature of $390^{\circ} \mathrm{C}$ among the six formulations tested. Other formulations had glass transition temperatures $\left(T_{\mathrm{g}}\right)$, ranging between 280 and $300^{\circ} \mathrm{C}$. However, there were no significant changes in crystallization and melting temperatures of the composites. The mechanical properties of the composites showed a high compressive and impact strength. For example CS 60-40 showed an optimum impact resistance of $97 \%$, compressive strength of $8.7 \mathrm{MPa}$ and a flexural strength of $2.5 \mathrm{MPa}$ as a results of highly dispersed kaolin in the polymer matrix.

From the observed microstructural properties, thermal resistance, and mechanical characteristics, we propose that these vegetable oil based composites could be used in large scale production techniques of composites for application in the construction industry based on a 60/40 threshold polymer/filler amount.

\section{Acknowledgment}

The authors appreciate Mrs. Afua Yeboah, Research Administrator of ORID for the support in the procurement of laboratory equipment for the research. They again acknowledge Mr. Emmanuel Frempong Brenyah, the Chief Technician in the Department of Materials Science and Engineering, for his immense assistance in the laboratory.

\section{References}

1. A. Yaya, D. Dodoo-Arhin, J.K. Efavi, and D.S. Konadu, ARPN J. Eng. Appl. Sci., 7, 10 (2012).

2. Y.D. Bensah, B. Agyei-Tuffour, L.N.W. Damoah, and J.K. Efavi, ARPN J. Eng. Appl. Sci., 7, 723 (2012).

3. P.H. Nam, P. Maiti, M. Okamoto, and T. Kotaka, Polym. Eng. Sci., 42, 468 (2002).

4. M. Alexandre and P. Dubois, Mater. Sci. Eng., 28, 1 (2000).

5. L.N. Luduena, V.A. Alvarez, and A. Vasquez, Mater. Sci. Eng. A. 121, Vol 460-461 (2007).

6. R. Anjana and K.E. George, Int. J. Eng. Res. Appl., 2, 868 (2012).

7. X. Wang, Q. Wu, J. Dong, Y. Hu, and Z. Qi, J. Appl. Polym. Sci., 85, 2913 (2002).

8. V. Mitttal, Materials 2, 992 (2009).

9. J. Heinemann, R. Reichert, R. Thomann, and R. Mulhaupt, Macromol. Rapid Commun., 20, 423 (1999).

10. L. Fowden, R.M. Barrer, and P. B. Tinker. Clay Minerals: Their Structure, Behaviour and Use, The Royal Society, London (1984).

11. F. Bertini, M. Canetti, G. Leone, and I. Tritto, J. Anal. Appl. Pyrolysis 86, 74 (2009).

12. S.G. Lei, S.V. Hoa, and M.-T. Ton-That, Compos. Sci. Technol. 66, 1274 (2006).

13. T. Tsai, S. Lu, C. Liu, C. Huang, H. Tsai, and J. Lin, Modified Clay and Clay-Polymer Composite, United States Chung Yuan Christian University (Jhongli City, TW), China Glaze Co., Ltd. (Hsinchu, Tw) 20090317627 (2009).

14. E.M. Araujo, R. Barbosa, A.W.B. Rodirgues, T.J.A. Melo, and E.N. Ito, Mater. Sci. Eng. A 445, 141 (2007).

15. J.P. Cline, R.D. Deslattes, J.L. Staudenmann, E.G. Kessler, L.T. Hudson, A. Hennins, and R.W. Cheary, NIST Certificate, SRM 660a "Line Position and Line Shape Standard 
for Power Diffraction," Gaithersburg USA, NIST Standard Reference Materials Program, NIST, USA (2000).

16. G. Caglioti, A. Paoletti, and F.P. Ricci, Nuclear. Instrum. Methods. Phys., 3, 223 (1958).

17. C. Liqiang and I.W. Seong, Polym. Bull., 61, 453 (2008).

18. D. Hinckley, Clays Clay Miner., 11, 229 (1963).

19. P. Scherrer, Math. Phys., Kl., 2, 98 (1918).

20. M.D. Guillén and N. Cabo, J. Sci. Food Agric., 75, 1 (1997).

21. L.D. Pavia, G.M. Lampman, and G.S. Kriz, Introduction to Infrared Spectroscopy, 3rd ed., Thomson Learning, Victoria, Australia, 13 (2001).

22. A.N. Lazarev, Vibrational Spectra and Structure of Silicates, New York, Plenum, 178 (1972).

23. R.M. Silverstein and F.X. Webster, Spectrometric Identification of Organic Compounds, 6th Ed., Wiley, New York, 71 (1996).
24. V.C. Farmer and J.D. Russell, Spectrochim Acta, 20, 1149 (1964).

25. R.L. Ledoux and J.L. White, Science 145, 47 (1964).

26. P.G. Rouxhet, N. Samudacheata, H. Jacobs, and O. Anton, Clay Miner., 12, 171 (1977).

27. K. Wada, Clay Miner. 7, 51 (1967).

28. J.L. White, A. Laycock, and M. Cruz, Bull. Groupe Franc. Argiles, 22, 157 (1970).

29. A.M. Boriek, J.E. Akin, and C.D. Armeniades, J. Compos. Mater., 22, 986 (1988).

30. S.N. Mustafa and Diyala, J. Eng. Sci., 05, 162 (2012).

31. J. Jordan, K.I. Jacob, R. Tannenbaum, M.A. Sharaf, and I. Jasiuk. Mater. Sci. Eng. A, 393, (2005).

32. L. Domka, A. Malicka, and N. Stachowiak, Acta Phys. Polonica. A, 114, 413 (2008). 